\title{
Studies on the Automatic Card Stripper
}

\author{
Researches on the Performance of the Belt-Type \\ Automatic Card Stripper
By Yasushi Niitsu*, Seiichi Suzuki ${ }^{* *}$ and Akira Yoshikawa ${ }^{* * *}$
**** Member, Faculty of Engineering, Osaka University
** Member, Nihon Spindle Mfg. Co., Ltd.

\begin{abstract}
Presented in this article are the results of a performance test of the belt-type automatic card stripper designed by us. The results are:

1. The variation in the weight of the card sliver has been shown to be not significant, irrespective of what the period of the nozzletraverse is.

2. The yield of the card sliver increases and the nep counts decrease.

The the belt-type is simpler in biuld than the other ACS's (for "automatic card strippers") which we have previously tested.
\end{abstract}

\section{How Built}

The belt-type ACS is so designed that the nozzle traverses continuously in one direction at regular and constant time-intervals, which its stroke equals to the width of the cylinder. For this reason, the variation of card sliver is not significant.

The belt-type ACS has fewer accessories and parts than other ACS, and therefore, gives a more accurate performance.

A schematic view of the main part of the belt-type ACS is shown in Figure 1. The

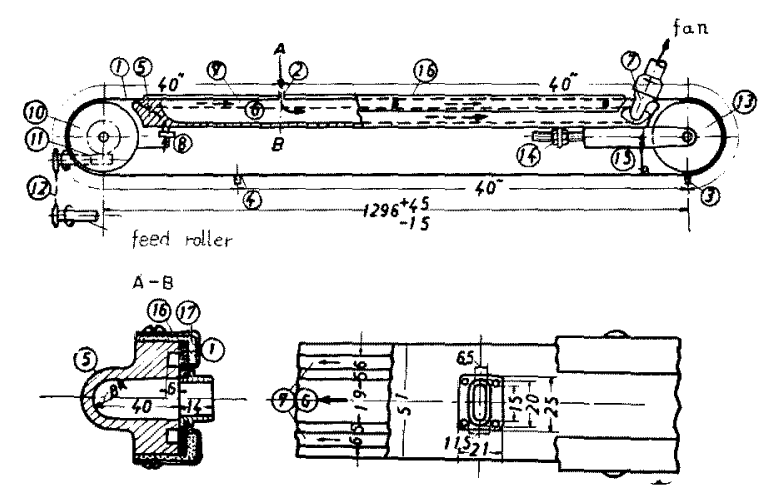

Fig. 1 Schematic view of Belt-Type ACS

illustration shows (1) thin vinyle or steel belt, (2), (3), (4) suction nozzles (the distance between nozzles is equal to the width of the card cylinder), (5) hollow bilge-type casing, (6) main ditch to convey sucked strips, (7) exhaust port, (8) air suction cap with filter for the narrow ditch, (9) narrow ditch to extract cotton dust from the part between the casing and the belt, (10) driving pulley, (11) worm gear, (12) chain, (13) following pulley, (14) set screw to give suitable tension to the belt, (15) brush to clean the inside of the belt, (16) angle-shaped steel plate to press the belt and (17) felt.

The belt-type ACS is set in the space above the taker-in, where the slender part of the back seat is cut off. Figure 2 shows a sketch of

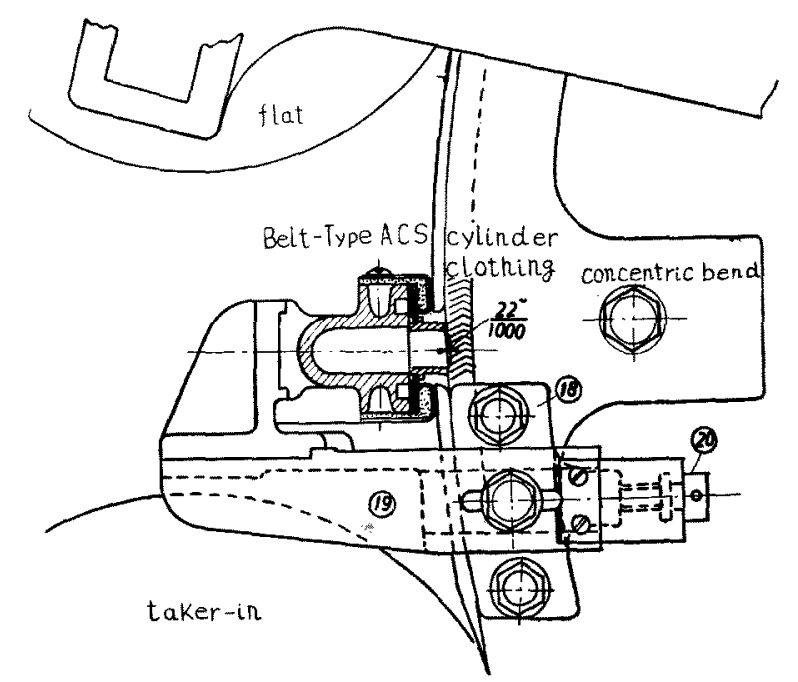

Fig. 2 Sketch of installation of Belt-Type ACS

the authors' belt-type ACS set on the carding machine, (18) is the rack for fitting at the concentric bend, (19) is the stand on which ACS is placed, (20) is the set screw to keep the gap between the top of the cylinder clothing and the suction nozzle in the regular gauge.

Photos of the belt-type ACS in oparation are given in Figures 3 and 4 . It is easier to set the ACS in the position above the takerin, as shown in these Figures. Therefore, no reciprocating motion of the rubber pipe is necessary and the removal of cotton waste from the position under the undercasing is easy. 


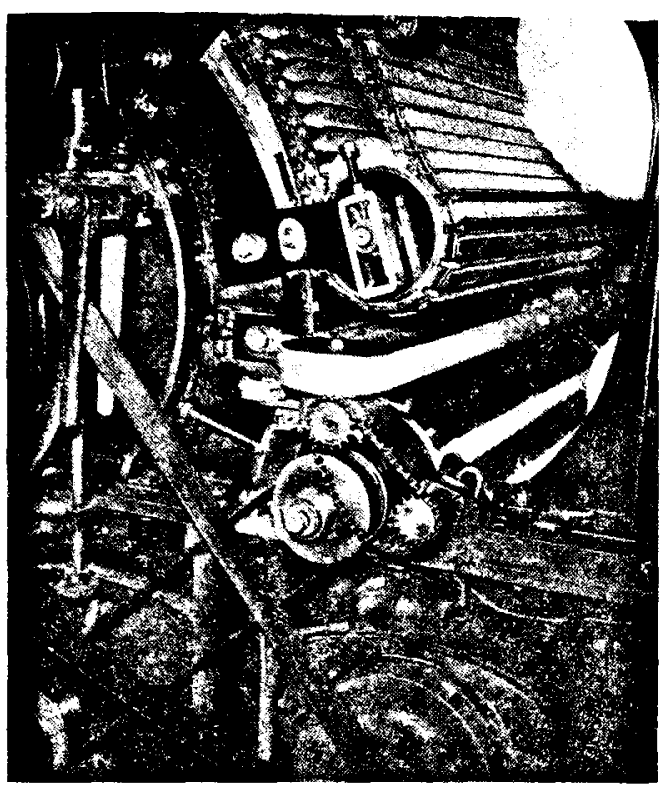

Fig. 3 Driving side of Belt-type ACS in operction

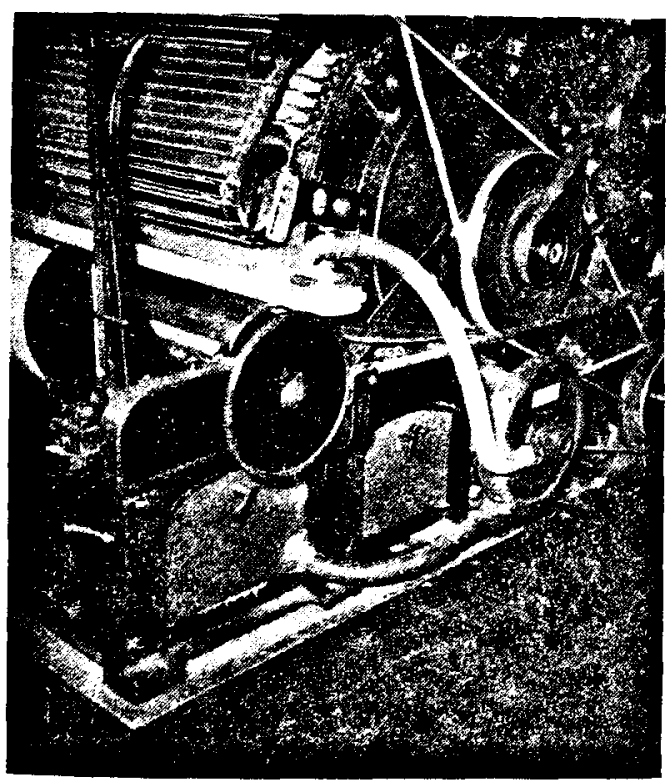

Fig. 4 Fan side of Belt-typeACS in operation

2. Chracteristics of the Suction Nozzle of the Belt-type ACS

The suction nozzle is placed at the prescribed distance of $22 / 1000$ inches from the surface of the cylinder clothing. The relation between the air flow and the static pressure of the pressure tap in the center of the casing is shown in Figure 5. $V_{0}$ in this figure shows the air flow when the steel plates which press the belt (shown in Figure 1, "(16)") are removed and the belt is sucked only by suction pressure. $V$ shows the air flow when the steel plates

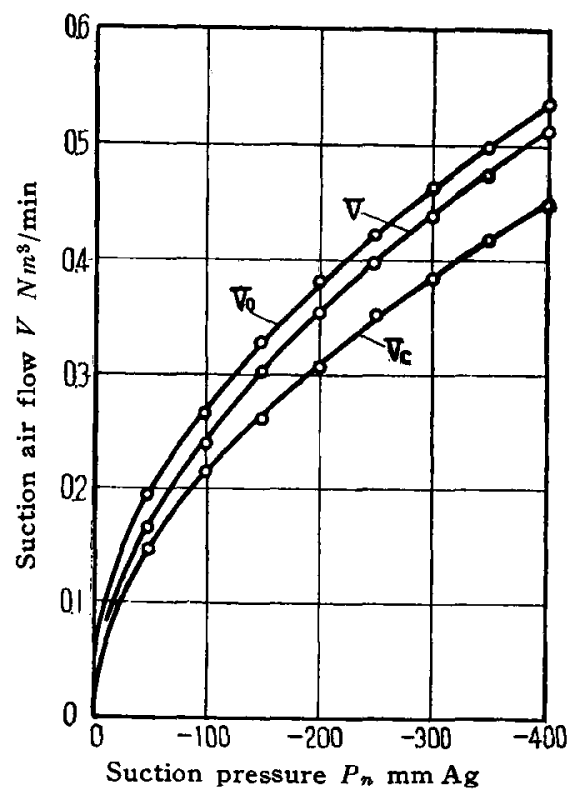

Fig. 5 Relations between suction static pressure and suction air flow under the some conditions of belt and casing

are set. $V$, shows the air flow when the gap between the belt and the casing is filled completely with the rubber tape.

The air flow of $V_{0}$ or $V$ is larger than $V_{e}$. The difference between them is due to penetration through the gap. Tendencies of the penetration are shcwn in Figure 6 . The curve

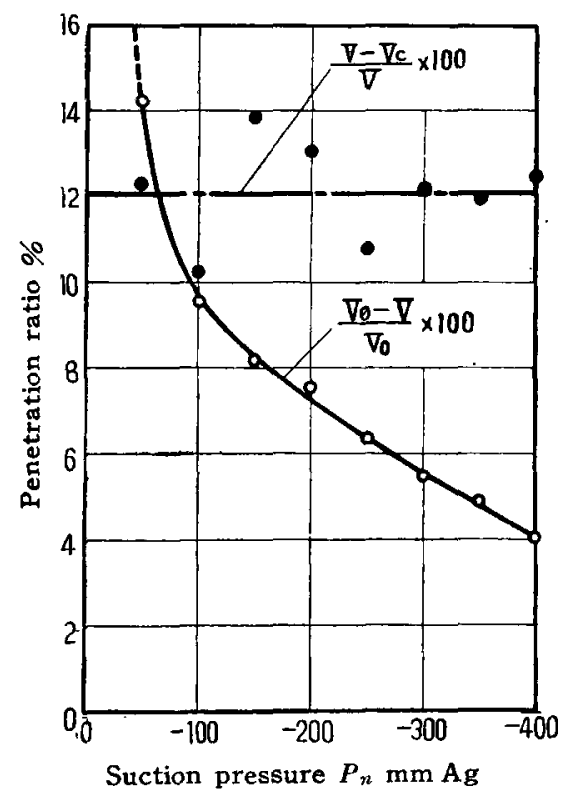

Fig. 6 Tendencies of penetration against suction pressure

in this figure shows the penetration ratios of $V_{0}$ and $V$. The quantity of the penetration is almost constant. Accordingly, its ratio decreases as the vacuum gets higher. This 
phenomenon is caused because the belt, being flexible, sticks closely to the casing when the vacuum is high. The steel plates which press the belt are useful for reducing the penetration by about $10 \%$.

The relation between $V$ and $V_{r}$ is explained thus: The quantity of the penetration increases as sucked air flow increases. The ratio of the quantity of the penetration remains almost constant. It is considered that this penetration cannot be reduced by the steel plates but can be reduced only by an improvement in the materials of which the belt and casing are made and by an improved method of processing those materials.

Table 1 shows the various calculated values

Table 1

Air flow at opening ….................. $V_{0}=0.384 \mathrm{~N} \mathrm{~m}^{3} / \mathrm{min}$

Air flow with steel plates and with

narrow ditch opened ................. V $=0.354 \mathrm{Nm}^{3} / \mathrm{min}$

Air flow when the narrow ditch is

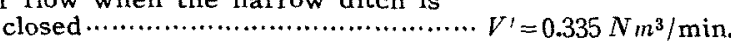

Air flow through the narrow ditch................................. $-V^{\prime}=0.019 \mathrm{~N} \mathrm{n}^{3} / \mathrm{min}$

Ratio of air flow through the narrow ditch …….............. $(V-V) / V=5.37 \%$

Air velocity through the main ditch $\cdots w=9.54 \mathrm{~m} / \mathrm{sec}$.

Air velocity through the narrow ditch $\cdots w=4.40 \mathrm{~m} / \mathrm{sec}$.

Ratio of reduction of penetration

due to the steel plates.....( $\left.V_{0}-V\right) / V_{0}=7.79$ \%

Mean air velocity through the suction

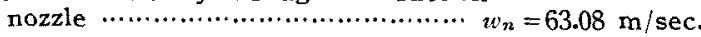

when suction pressure is $-200 \mathrm{~mm}$ Aq.

\section{Conditions for Operating Carding Machine}

The condition we have used for operating the carding machine in our experiment are shown in Table 2.

Table 2

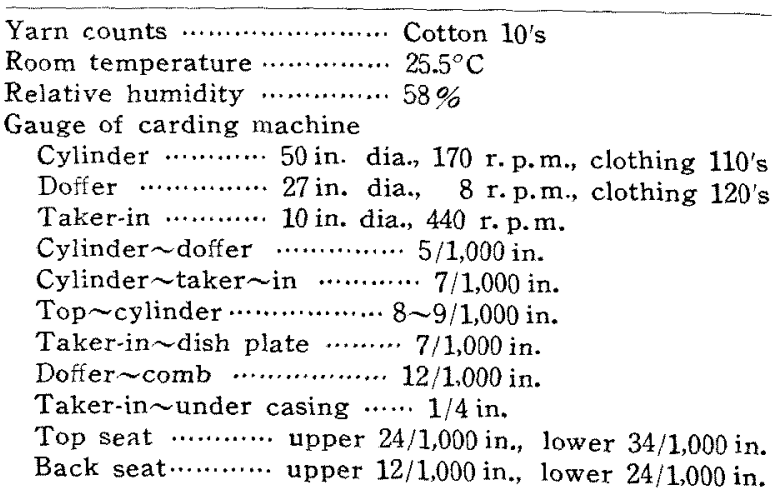

The accumulating characteristics of the strips in this machine are shown in Figure 7.

The following equation shows the relation between the weight $S_{c} g$ of the cylinder strips and the length $t$ min. of time taken for the

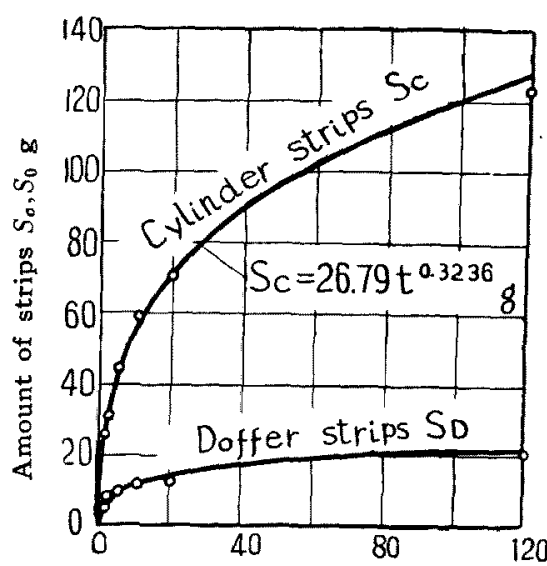

Length of time after usual stripping without Belt-type ACS $t \mathrm{~mm}$

Fig. 7 Characteristics of carding load

experiment.

$$
S_{c}=26.79 t^{0.3336} \mathrm{~g}
$$

\section{Sliver Output}

We have measured the sliver output and various forms of waste for (1) the usual intermittent stripping and (2) for stripping with the belt-type ACS at various periods of traverse. Table 3 shows the ratios of the sliver output

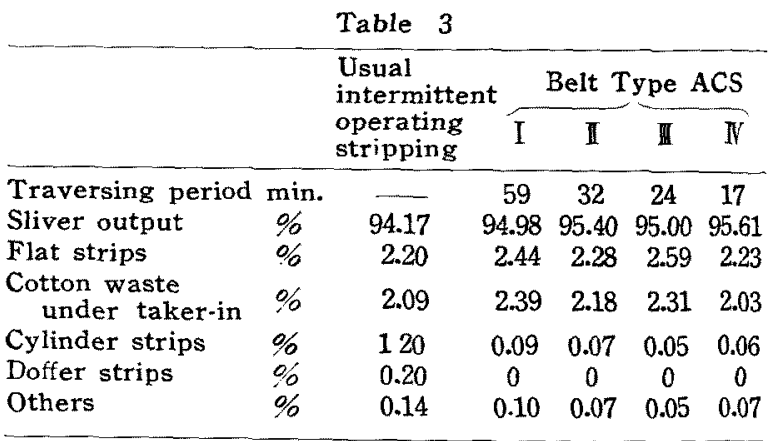

Suction pressure we kept at $-216 \mathrm{~mm} \mathrm{Aq}$.

and the quantity of the waste to fed cotton.

In this table, cylinder strips and doffer strips for the belt-type ACS are the values that are distributed only over the length of time of the experiment. The quantity of these strips cannot be measured, because carding machines equipped with belt-type ACS are cleaned only once a day the 16 working hours. (They are cleaned with a wire brush to remove cotton seeds and other impurities.)

Installation of the belt-type ACS increases sliver output somewhat, irrespective of the traversing period.

The cylinder strips sucked with a belt-type ACS fan are shown in Table 4.

As already reported, the theoretically ideal width for a suction nozzle is $0.2 \sim 0.4 \mathrm{~mm}$, but the belt-type ACS has a suction nozzle $6.5 \mathrm{~mm}$ in width for practical purposes. Therefore, 
strips sucked in our experiment and shown in Table 4 are about $150 \%$ of the quantity of the

Table 4

I II II IV IV

$\begin{array}{lllll}\text { Experimentally sucked strips } \mathrm{g} / \mathrm{min} & 2.92 & 3.70 & 4.71 & 5.76\end{array}$

$\begin{array}{llllll}\text { Theoretically calculated strips } \mathrm{g} / \mathrm{min} & 1.70 & 2.57 & 3.12 & 3.94\end{array}$

calculated strips. The sucked strips tend to increase as the traversing period shortens.

From a comparison of the sucked strips which are returned and those which are not, we find 91 95\% of the sucked strips are reproduced in the form of sliver. Consequently, sliver output does not decrease even if the traversing pericd shortens.

\section{Evenness of Sliver}

We have weighed the per-minute output of sliver, with the results shown in Figure 8.

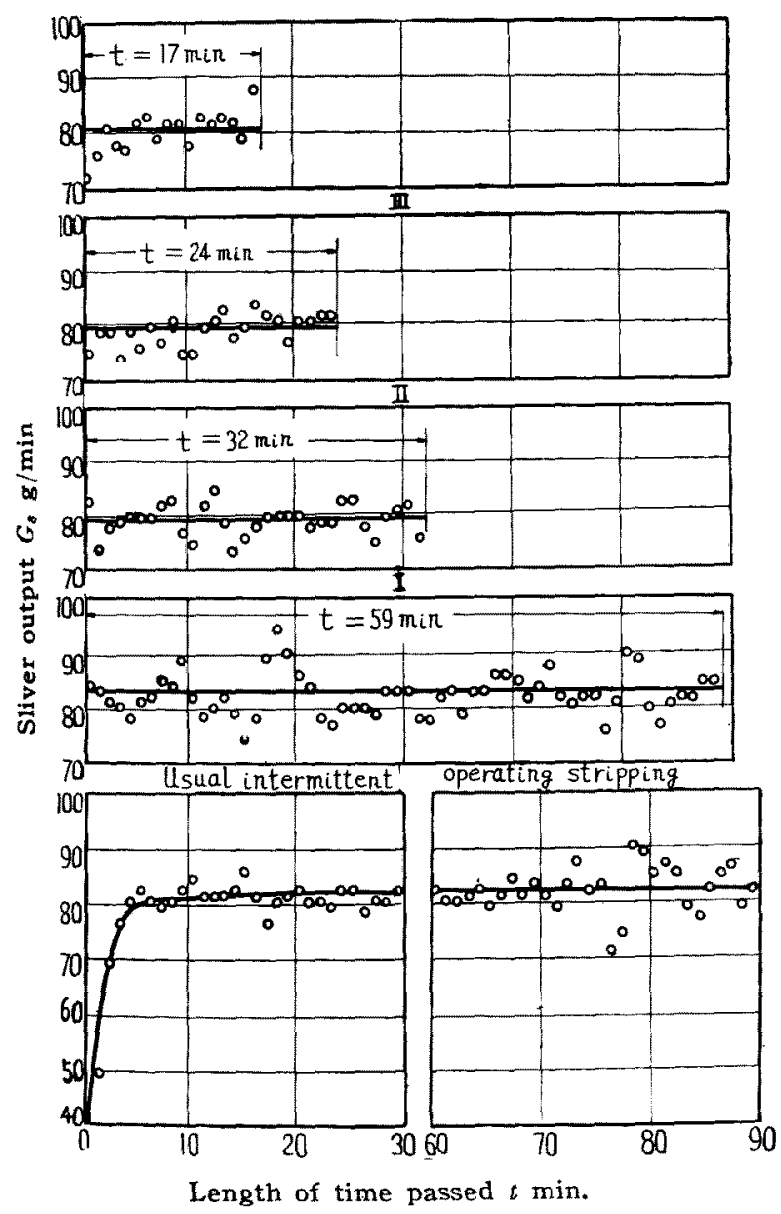

Fig. 8 Per-minute Sliver output for card with and without Belt-type ACS

Irrespective of the traversing period, the belttype ACS does away with the peculiar sliver unevenness caused by other types of ACS, as already reported. This fact is one of the distinctive features of the belt-type, which is evident on comparison with the results obtained from ACS of the constant speed reciprocating type.

Unevenness of sliver output, which is evaluated by the Sommer system, is $3.54 \%$ for the usual intermittent operating stripping, and is I... $4.62 \%, \mathbb{I} \ldots 2.81 \%$, II ...2.91\% and IV ... 3.50 $\%$ for stripping with the belt-type ACS.

Sliver too light in weight, which turns up just after the usual intermittent stripping, is eliminated by the belt-type. The belt-type ACS produces uniform sliver for many hours running and promotes the operating efficiency of the carding machine, as already reported.

\section{Nep Count}

A carding machine not equipped with the belt-type ACS is put in operation after the usual stripping with a wire brush. For experimental purposes, we picked up sample webs from five positions of the card web at 0,30 , 60,90 and 120 minutes after the beginning of operation and placed those sample wrebs on 10 wooden plates of size 6 inches $\times 6$ inches. Tendencies of increase of the impurities contained in the sample webs are shown on the right-hand side of Figure 9.

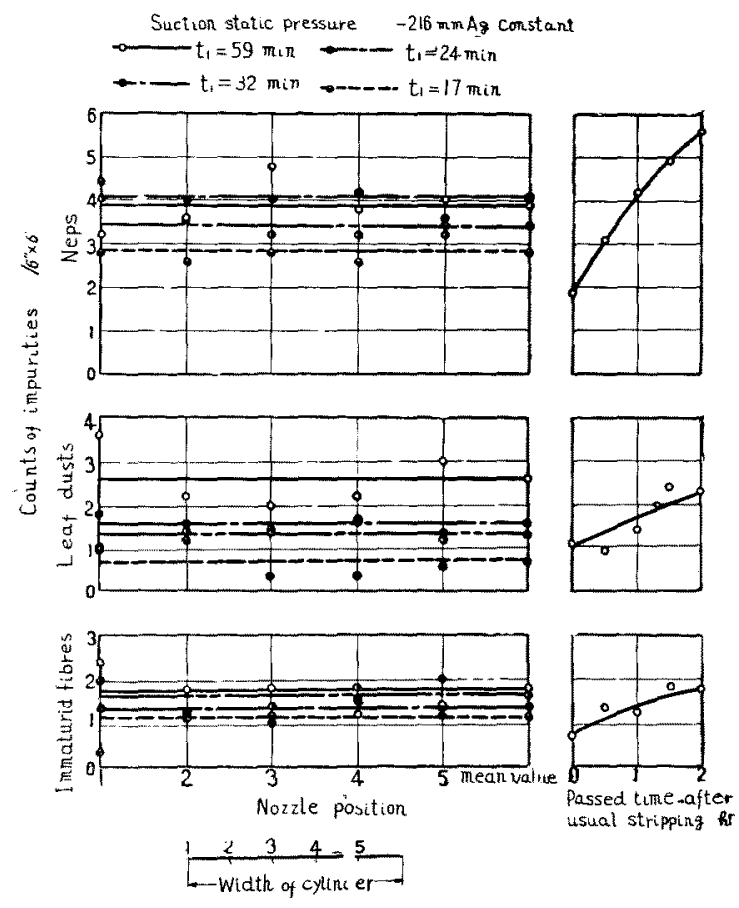

Fig. 9 Counts of impurities contained in web produced by card with and without Belt-type $A C S$

We also picked up sample webs from a carding machine equipped with the belt-type ACS when the suction nozzle had travelled every one-fifth of the traversing stroke. The 
results obtained are shown on the left-hand side of Figure 9.

The mean counts of the impurities contained in the sample webs picked up from the five positions of the card web of the carding machine equipped with the belt-type ACS are almost uniform, irrespective of the nozzle position. Nep counts decrease as the traversing period shortens. When the period gets to about 20 minutes, the carding machine keeps producing excellent sliver such as is produced within 30 minutes after the usual stripping without the belt-type ACS.

The results for the carding machine without ACS, whether belt-type or any other type, tabulated according to the positions from which the sample webs were picked up, shcw total nep counts of $40,39,39,39$ and 41 respectively. It is considered, then, that the production of neps is not affected by the position of card clothing.

From the relation between the position from which samples are picked up and the position of the traversing nozzle, we can understand how much time passes - after the passage of the suction nozzle - in a position from which samples are picked up. The average values figured according to passed strokes after the passage of the suction nozzle are shown in Figure 10. Nep counts increase gradually even

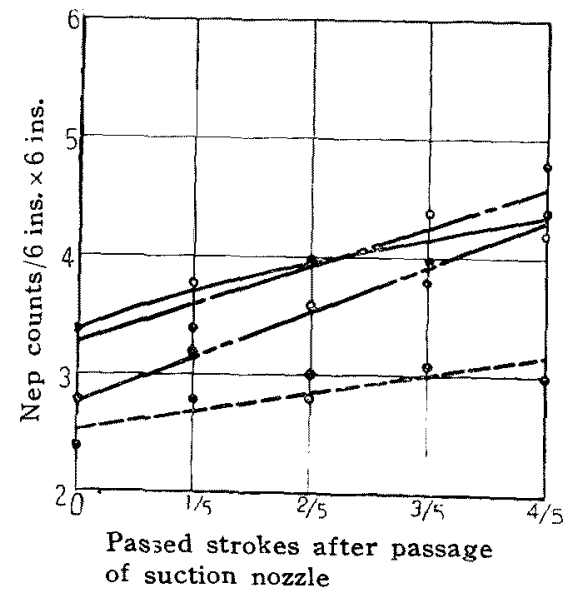

Fig. 10 Increase of neps with passage of time after stripping by Belt-type ACS nozzle

during the short traversing period, as nep counts increase according to the length of time that passes after stripping with a carding machine without the belt-type ACS. Therefore, to reduce neps, it is desirable that the traversing pericd be as short as possible.

Keeping the traversing pericd at a constant
17 minutes, we made the same experiment under three different degrees of suction pressure, $-280,-216$ and $-153 \mathrm{~mm} \mathrm{Aq}$, and obtained the results shown in Figure 11. No significant difference is seen in this range of suction pressure.

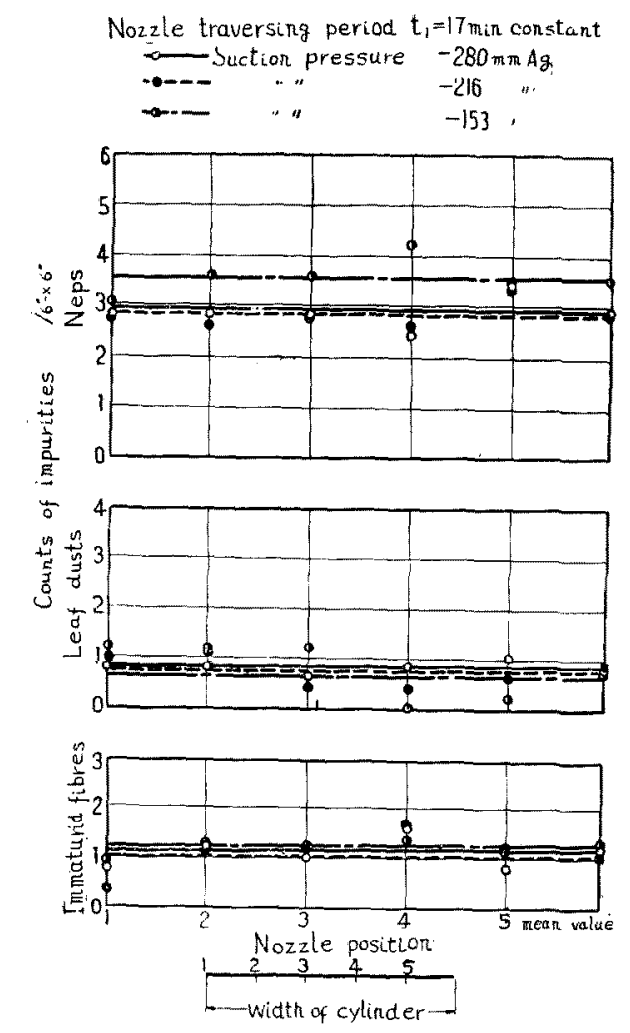

Fig. 11 Counts of impurities contained in web when suction pressure is varied

The characteristics of the belt-type ACS are summed up as follows:

(1) The belt-type is simpler in build than two other types of ACS and, therefore, gives accurate operations.

(2) Excellent sliver can be produced constantly, because the peculiar sliver irregularity caused by the other types of ACS does not occur even if the traversing period is short.

In this report, we have described only the more distinctive characteristics of the belt-type ACS. Its general properties are referred to in our last report. [l]

\section{Literature cited}

[1] Y. Niitsu, S. Suzuki, A. Yoshikawa, Journal of the Text. Mach. Soc. Japan, English edition, Vol. 1, No. 1, p. 39, (March 1955) 